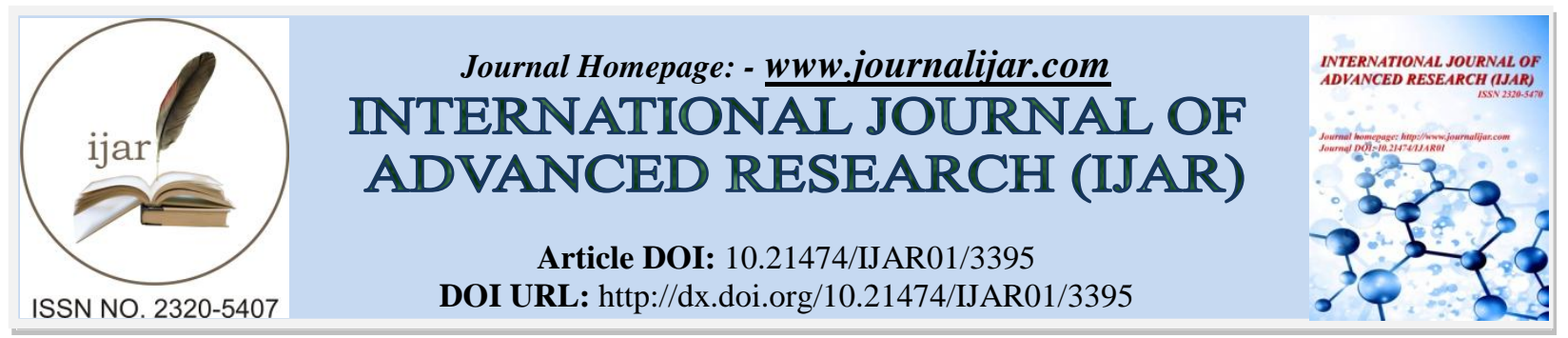

RESEARCH ARTICLE

\title{
SYMPTOMATIC ESOPHAGEAL WEB: A DIAGNOSTIC CLUE TO EPIDERMOLYSIS BULLOSA- CASE SERIES FROM PAKISTAN.
}

Shayan Sirat Maheen Anwar, Fahd Haroon, Muqaddas Anjum, Muhammad Anwar Adil and Haji Haroon. Karachi X-rays/CT Scan Centre, 296 M.A Jinnah Road Opposite Mazar-e-Quaid Karachi.

\section{Manuscript Info}

Manuscript History

Received: 15 December 2016

Final Accepted: 13 January 2017

Published: February 2017

Key words:-

Esophageal web, epidermolysis bullosa,

barium swallow

\begin{abstract}
Esophageal webs are infrequently reported with epidermolysis bullosa. We are presenting two cases of epidermolysis bullosa with symptomatic esophageal webs and typical dermal and skeletal features. Esophageal webs were reported on barium swallow examination and retrospectively correlated with physical and lab findings to establish the diagnosis of epidermolysis bullosa.
\end{abstract}

Copy Right, IJAR, 2017,. All rights reserved.

\section{Introduction:-}

Webs are amongst the most common esophageal structural abnormalities and most of them are asymptomatic but they can produce progressive dysphagia. An esophageal web is a 1-2 mm thick, shelf like extension of normal esophageal mucosa and submucosa that can occur anywhere along the length of the esophagus but is typically located in the anterior wall of the cervical esophagus. ${ }^{[1]}$ Webs are seen in $5-15 \%$ of patients undergoing barium swallow study for the evaluation of dysphagia. ${ }^{[2]}$ Although most proximal esophageal webs are considered idiopathic several associations have also been described. Commonly they are observed in Plummer Vinson syndrome, but they are also associated with rare skin disorders such as epidermolysis bullosa (EB) or other bullous diseases. ${ }^{[2]}$ The overall incidence and prevalence of the disease is 8 per one million population in United States ${ }^{[3]}$ and 32 in 1 million in Northern Ireland. However prevalence rates in Middle East population is unknown. ${ }^{[4]}$

Here we are presenting two cases of epidermolysis bullosa and its association with symptomatic esophageal web formation with typical skeletal and skin features, but no family history. These cases were primarily diagnosed on barium swallow examination.

\section{Case I:-}

A boy aged 14, presented with complaint of progressive dysphagia for solids for past five years with recurrent episodes of sticking of food at cricoid level, no history of regurgitation of food or hematemesis was given. There was no history of caustic ingestion. At the time of birth he had few blisters on extremities and had history of recurrent blistering of skin with even minor trauma. Blisters were itchy and rupture easily leaving a reddened skin which heal with scarring. His parents had consanguineous marriage but had no family history of such skin diseases nor did he had any significant surgical history. Physical examination revealed generalized scarred skin secondary to ruptured blisters, including perineal region. There was clubbing of hand nails while toe nails were small with loss of big toe nails. There were contractures in hands leading to flexion of fingers. Some atypical skeletal features were also observed including small ears, pointed fingers and long wide palms giving appearance of claw hands. Small tongue with inability to protrude forward. Few superficial oral ulcers were found but there was no angular glossitis 
or dental carries. His hemoglobin level was $10 \mathrm{~g} / \mathrm{dl}$ (range 12-14 g/dl). A barium swallow was performed which showed two esophageal webs one at C4 and another at C7 with little hold up of contrast proximally. Endoscopy was suggested. He was diagnosed with epidermolysis bullosa on clinical grounds and was treated with different anti allergies and antibiotics; no immunosuppressant therapy was given. (Figure 1).

Figure 1:-
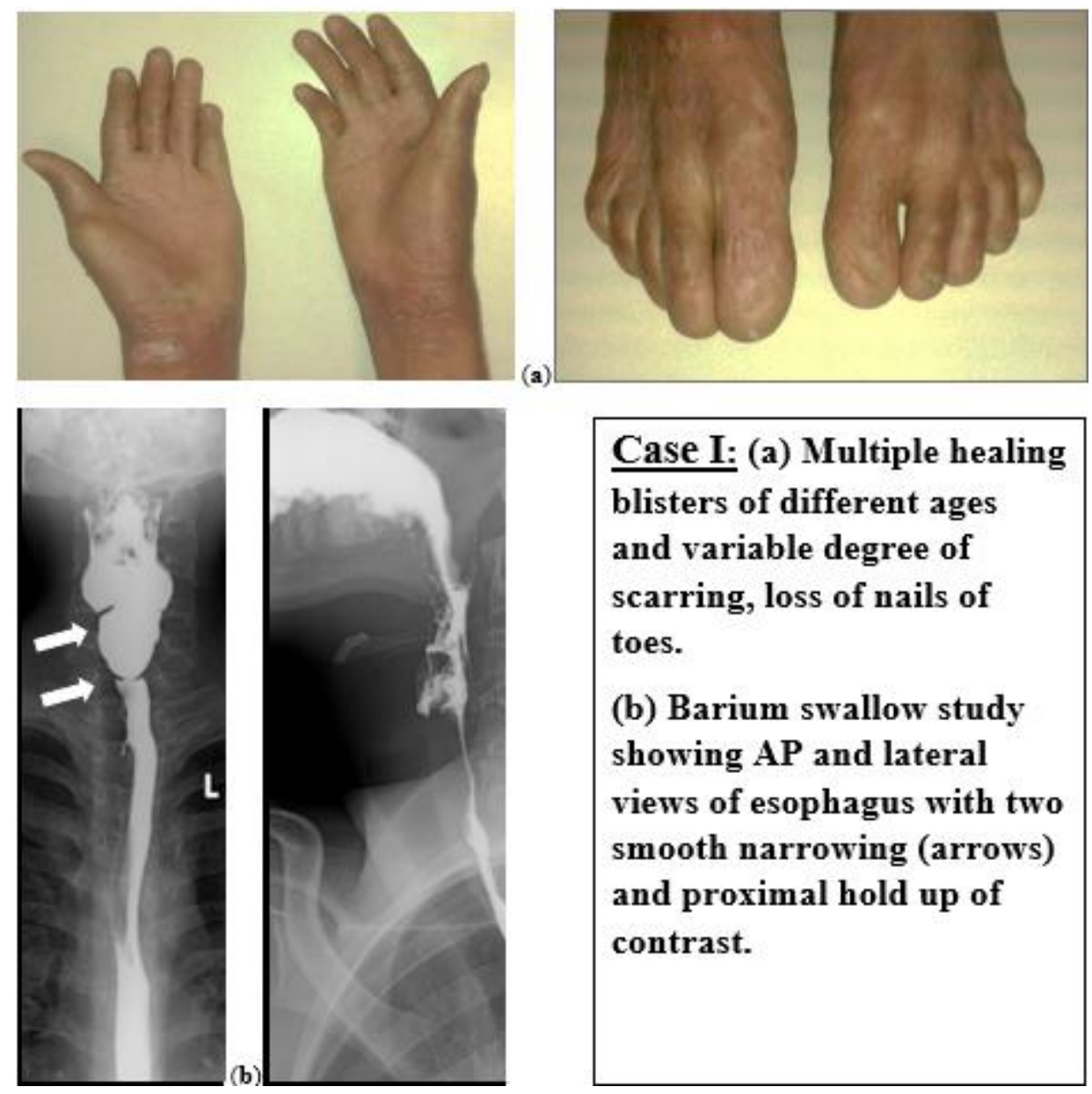

\section{Case I: (a) Multiple healing blisters of different ages and variable degree of scarring, loss of nails of toes.}

(b) Barium swallow study showing $A P$ and lateral views of esophagus with two smooth narrowing (arrows) and proximal hold up of contrast.

\section{Case II:-}

Second patient was a middle aged male presented with history of difficulty in swallowing for past 10 years gradually worsening. Only able to take soft diet for past 5years. His birth history revealed presence of blisters on skin and limb deformity at time of birth. Spontaneous blistering stopped after age of 20 years and now occurs rarely only after trauma. No biopsy was done and he did not receive any immunosuppressant therapy as well. His parent had consanguineous marriage. His three other siblings also had history of blistering of skin but it was mild, not associated with skeletal deformity and resolved spontaneously with time by age 15 to 20 years. On physical examination he also had scarred skin with fixed flexion at right wrist joint congenitally and flexion at metacarpophalangeal joints of both hands. Clubbing discoloration and deformity of nails of hands and feet. He gave history of oral soreness but no oral ulcers appreciated on examination. His hemoglobin level was 8 g/dl (range 12-14 $\mathrm{g} / \mathrm{dl}$ ). Skin biopsy for definitive diagnosis was advised but not performed due to affordability issue. He underwent barium swallow examination which showed multiple segments of circumferential smooth narrowing involving cervical esophagus and upper dorsal esophagus due to esophageal webs. (Figure 2). 
Figure 2:-
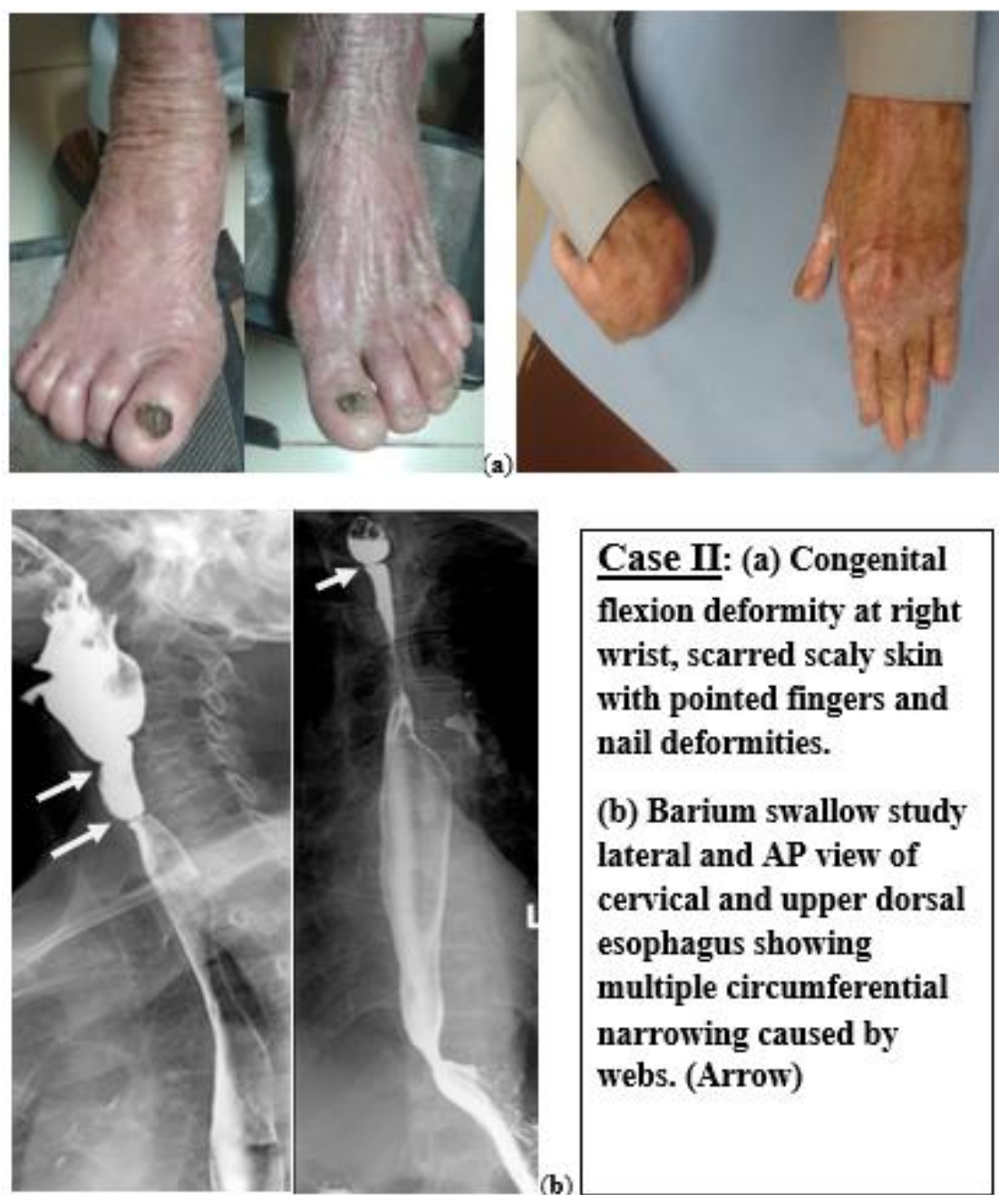

\section{Discussion:-}

Epidermolysis bullosa acquisita (EBA) is a well-defined, blistering disorder of the skin associated with autoantibodies to type VII collagen ${ }^{[5,6]}$ Esophageal involvement of EB was first described in 1929, including spectrum of manifestations, such as, diffuse inflammatory changes; disordered motility; bullae, ulcers, and mucosal scarring; webs; strictures; traction hiatal hernia and gastroesophageal reflux; complete obstruction of esophagus and perforation of esophagus. Webs are considered one of the earlier and milder manifestations. Dysphagia is reversible when caused by bullae or webs and permanent when due to strictures. ${ }^{[7]}$

Blistering of mucosa in epidermolysis bullosa is produced by minor trauma, but the actual mechanism behind this is not completely known. Presumably trauma from hot or rough foods causes separation of the esophageal epithelium from the lamina propria. Since the proximal third of the esophagus is the narrowest and least distensible, this might account for it being the most commonly affected segment. The distal third is the next most commonly involved, possibly because it is subject to both reflux gastric juice and pulsations of the heart and aorta ${ }^{[8]}$ Repeated blistering and healing probably results in fibrosis and stricture formation. As in our case blistering was improving with age but dysphagia caused by esophageal web was more troublesome for the patient. In a previously done case series of four patients by Marsden et all, it was observed that radiological examination is usually helpful when esophageal involvement is suspected. Radiological evidence of narrowing and irregularity of the upper third of the esophagus was present in all four patients of their study, while dysphagia severe enough to seek medical assistance was experienced by only two cases. Perhaps if all patients with epidermolysis bullosa were subjected to a routine barium swallow examination then esophageal involvement might be found to be more common than has been suspected. ${ }^{[8]}$ 
Our two patients remained un-diagnosed and were not given any immunosuppressant agent, therefore we can presume that early diagnosis and commencement of immune suppressive therapy could have prevented esophageal wear and tear and improve quality of life.

Nevertheless, barium swallow examination proved to be a diagnostic tool in our two cases, leading to early diagnosis of esophageal involvement and prompt treatment. It saved the patients from more advanced and debilitating condition of dysphagia due to esophageal stricture formation, complete obstruction or perforation.

\section{References:-}

1. David Sutton, Text book of radiology and imaging. $7^{\text {th }}$ edition, Edinburgh: Elsevier Science Limited; 2003.

2. Michael S. Smith. Diagnosis and Management of Esophageal Rings and Webs. Gastroenterol Hepatol (N Y). 2010 Nov; 6(11): 701-704.

3. Jo-David Fine. Rare disease registries-lessons learned from National Epidermolysis Bullosa registry. J Rare diseases 1996, 2;5-14

4. Judeh abu sa'd, Margarita Indelman, Ellen Pfendner et all. Molecular Epidemiology of Hereditary Epidermolysis Bullosa in a Middle Eastern Population. Journal of Investigative Dermatology (2006) 126, $777-$ 781.

5. Stewart MI, Woodley DT, Briggaman RA. Epidermolysis bullosa acquisita and associated symptomatic esophageal webs. Arch Dermatol. 1991 Mar; 127(3):373-7.

6. Chen M, Kim GH, Prakash L, et al.Epidermolysis bullosa acquisita: autoimmunity to anchoring fibril collagen. Autoimmunity. 2012 Feb; 45(1):91-101.

7. Agha FP, Francis IR, Ellis CN.Esophageal involvement in epidermolysis bullosa dystrophica: clinical and roentgenographic manifestations.Gastrointest Radiol. 1983; 8(2):111-7.

8. Marsden RA, Gowar FJ, MacDonald AF,et al. Epidermolysis bullosa of the oesophagus with oesophageal wed formation.Thorax. 1974 May; 29(3):287-95. 